\title{
The hepatic retinyl ester hydrolase activity is depressed at the onset of diabetes in $\mathrm{BB}$ rats
}

\author{
Min Chen ${ }^{1}$, Alan B. R. Thomson ${ }^{2}$, Andrew T. C. Tsin ${ }^{3}$ and Tapan K. Basu ${ }^{1 *}$ \\ ${ }^{1}$ Department of Agricultural, Food \& Nutritional Science and ${ }^{2}$ Department of Medicine, Division of Gastroenterology, \\ University of Alberta, Edmonton, Canada \\ ${ }^{3}$ Division of Life Sciences, University of Texas at San Antonio, San Antonio, Texas, USA
}

(Received 12 December 2001 - Revised 1 July 2002 - Accepted 6 September 2002)

\begin{abstract}
Dietary vitamin A as retinyl ester is hydrolysed and re-esterified with long-chain fatty acids in the small intestine. The esterified vitamin A is subsequently stored in the liver, where it is hydrolysed to free retinol to be transported by carrier proteins to the target tissue. A decreased availability of retinol carrier proteins has been suggested to be responsible for affecting metabolic availability of vitamin A in type 1 diabetes. Using BB Wistar rats, the present study was undertaken to examine whether the presence of a hyperglycaemic state modifies retinyl ester hydrolase (REH) activity in the intestine and the liver. At the onset of diabetes, hepatic REH enzymatic activity was significantly $(P<0.05)$ decreased. However, REH activity remained unaffected in the small intestine, including both ileum and jejunum. Diabetes also resulted in decreased plasma and liver concentrations of retinol. An in vitro study was conducted to examine the effect of diabetes on the intestinal uptake of retinyl palmitate. Jejunum and ileum from diabetic and non-diabetic BB rats were incubated with labelled retinyl palmitate at different concentrations ranging from 32 to $256 \mathrm{nmol} / \mathrm{l}$. The uptake of retinyl palmitate was increased in both diabetic and non-diabetic rats together with the increase of substrate concentration. However, no significant difference was observed in the uptake of retinyl palmitate between diabetic and non-diabetic rats. These present results suggest that the depressed hepatic REH activities may contribute to the diabetes-associated metabolic derangement of vitamin A.
\end{abstract}

BB rats: Diabetes: Vitamin A: Retinyl ester hydrolases: Intestinal absorption

In recent years, there have been many studies reporting that the circulatory level of retinol is depressed in rats where diabetes is either induced by streptozotocin treatment (Tuitoek et al. 1996b) or spontaneously developed (Lu et al. 2000). The evidence of reduced plasma retinol level has also been demonstrated to occur in human subjects with type 1 diabetes (Basu et al. 1989; Krempf et al. 1991; Martinoli et al. 1993). The decreased plasma retinol is thought to be secondary to its impaired transport from hepatic storage, as shown by decreased plasma concentrations of retinol carrier proteins (e.g. retinol-binding protein (RBP) and transthyretin) in hyperglycaemic human subjects (Basu et al. 1989) and animals (Tuitoek et al. $1996 a$ ). It is also noteworthy that supplemental intakes of vitamin A result in an accumulation of the vitamin in the liver, without altering its plasma levels, in hyperglycaemic rats (Tuitoek et al. 1996b). A significant $(P<0 \cdot 05)$ decrease in the abundance of RBP mRNA has been reported at the onset of diabetes in $\mathrm{BB}$ rats $(\mathrm{Lu}$ et al. 2000), suggesting a possible effect on the synthesis of the carrier protein.

Dietary vitamin A as retinyl ester is first hydrolysed to retinol by pancreatic esterase before it is absorbed by the intestinal mucosa (Ong, 1993). Retinol is subsequently re-esterified with long-chain fatty acids in the enterocyte, incorporated into chylomicrons, and finally transported to hepatic stellate cells for storage. Prior to transport to the target tissues (such as retina of the eye), retinyl esters are hydrolysed to retinol, which then binds to RBP produced by the liver (Blomhoff et al. 1990). Retinol is mobilized from its hepatic store and secreted into the circulation as retinol-RBP complex (holo-protein). The holo-protein normally circulates in the plasma as a molar complex with transthyretin. At target tissues, transthyretin is

\footnotetext{
Abbreviations: BBd, diabetic BB Wistar rat; BBdp, diabetes-prone BB Wistar rat; BBn, non-diabetes-prone BB Wistar rat; CHAPS, 3-((3cholamidopropyl)dimethylammonio)-1-propane-sulfonate; RBP, retinol-binding protein; REH, retinyl ester hydrolase.

* Corresponding author: Dr Tapan K. Basu, fax +1 780492 9130, email tbasu@afns.ualberta.ca
} 
released and RBP facilitates the uptake of retinol by RBP receptors. Retinol binds with cellular RBP, which facilitates the transport of retinol. It appears that retinyl ester hydrolysis is involved in the digestion and intestinal absorption of vitamin A as well as its hepatic uptake, storage and mobilization. The relationship between diabetes and retinyl ester hydrolysis has not been adequately studied. It is possible that the vitamin A homeostasis in the presence of diabetes is affected not only by altering retinol carrier proteins, but also retinyl ester hydrolases (REH).

A number of REH have been described in many different tissues, including intestinal mucosa, pancreas, liver, kidney, lung and the eye (Harrison \& Gad, 1989; Gueli et al. 1991; Rigtrup \& Ong, 1992). There also appear to be several biochemically distinct REH in various subcellular fractions of the liver. Moreover, some other hepatic enzymes can function as REH, including non-specific carboxylesterase, carboxylester lipase and lipoprotein lipase (Mentlein \& Heymann, 1987; Chen et al. 1997). Using BB Wistar rats, which are genetically predisposed to diabetes (Hosszufalusi et al. 1993), the present study was undertaken to examine the changes in the activities of some of the REH involved in the metabolism of vitamin $\mathrm{A}$, and to determine the influence of diabetes on the in vitro intestinal uptake of varying concentrations of retinyl palmitate.

\section{Materials and methods}

\section{Animals and diets}

All the chemicals were purchased from Sigma Biochemicals (St Louis, MO, USA) or Fisher Scientific (Pittsburgh, PA, USA) unless otherwise stated. The animal protocol was approved by the Animal Policy and Welfare Committee, University of Alberta. Diabetes-prone BB Wistar (BBdp) and non-diabetes-prone $\mathrm{BB}$ Wistar $(\mathrm{BBn})$ rats were obtained from the breeding colony of the Department of Agricultural, Food and Nutritional Science, University of Alberta. The original breeding pairs were obtained from Health Canada (Animal Resources Division, Health Protection Branch, Ottawa, Canada). Generally, the rats in BBdp lines are known to develop diabetes between 60 and $120 \mathrm{~d}$ of age (Logothetopoulos et al. 1984; Parfrey et al. 1989) with a diabetes incidence of 30-90\% (Baudon et al. 1989) and equal occurrence of the disease in both sexes (Bach, 1988). The diabetes-resistant BBn lines, on the other hand, do not develop diabetes spontaneously; they are used as controls for the BBdp rats. At weaning ( $21 \mathrm{~d}$ old), all rats were housed individually in stainless-steel cages in a temperature- and humiditycontrolled animal room with a $12 \mathrm{~h}$ light-dark cycle. Rats were given NIH-07 diet (Ziegler Brothers, Gardner, PA, USA) and water ad libitum. The diet contained $(\mathrm{g} / \mathrm{kg})$ : carbohydrate 514 , fat 52 , protein 215 , with the remaining weight accounted for by moisture and nonmetabolizable solids. The vitamin A content of the diet was $2.06 \mathrm{mg} / \mathrm{kg}$ diet (as retinyl acetate).

Body weight and food intake were monitored at regular intervals throughout the study. The rats (seventeen BBdp and seventeen $\mathrm{BBn}$ rats) were transferred to metabolism cages after the age of $50 \mathrm{~d}$. In BBdp rats the urinary glucose was measured three times per week using Testtape (Eli Lilly Canada Inc., Toronto, ON, Canada) until they reached the age of $120 \mathrm{~d}$. The daily blood glucose level, in a fed state, was measured using a glucometer (Ames Miles, Toronto, Ont., Canada) in a sample taken from the tail vein. Rats displaying glucosuria and subsequently hyperglycaemia (non-fasting plasma glucose $>13 \mathrm{~mm}$ ) were considered as being at the 'onset' of diabetes. BBdp rats at the onset of diabetes were described as diabetic $\mathrm{BB}(\mathrm{BBd})$ rats. Each newly diagnosed $\mathrm{BBd}$ rat, together with one age- and sex-matched BBn rat, was killed on the next morning of the diabetes onset, following an overnight fast. In addition to these animals, rats from both BBdp and BBn (age- and sex-matched) were killed at the age of 30 and $50 \mathrm{~d}$ (ten BBdp and ten BBn rats at each time point). Rats were first anaesthetized with $5 \%$ halothane (Halocarbon Laboratories, River Edge, NJ, USA); a blood sample was collected via cardiac puncture in heparinized tubes, followed by a termination via cervical dislocation. Liver and intestinal segments (jejunum and ileum) were quickly removed, rinsed with cold saline $(9 \mathrm{~g}$ $\mathrm{NaCl} / \mathrm{l}$ ) and blotted. The retina of the eye was isolated by the method of Uehara et al. (1989). The liver, intestine, retina, and the separated plasma were stored at $-70^{\circ} \mathrm{C}$ until analysis. For an in vitro study of the intestinal uptake of retinyl ester, separate groups of $\mathrm{BBd}$ and ageand sex-matched $\mathrm{BBn}$ rats (six per group) were killed using euthanol injection; intestinal segments (jejunum and ileum) were removed, flushed with ice-cold saline buffer, and used immediately (see later for details).

\section{Vitamin A determination}

Plasma and hepatic free retinol, and hepatic retinyl palmitate were analysed by reverse-phase HPLC according to the methods of Tuitoek et al. (1996b) and Wang et al. (1998) with minor modifications. The liver tissues were homogenized with ice-cold $0.05 \mathrm{M}-\mathrm{PBS}$ buffer $(\mathrm{pH} 7.4)$ in a polytron homogenizer (Brinkmann, Westbury, NY, USA). Samples of liver homogenates and plasma were extracted without saponification using butanol:ethyl acetate (1:1, v/v). Internal standard (retinyl acetate) was added to the samples before the extraction. A portion of the extract was injected into a Variane 5000 gradient reverse phase HPLC system (Variane Canada Ltd, Mississauga, Ont., Canada) with a $5 \mu \mathrm{m}$ Supelcosil LC-18 column $(4.6 \times 150 \mathrm{~mm}$; Supelco, Oakville, Ont., Canada). The HPLC mobile phase was acetonitrile-tetrahydrofuran-water (solvent A 50:20:30, by vol; solvent B 50:44:6, by vol, with ammonium acetate $(10 \mathrm{~g} / \mathrm{l})$ and acetic acid $(3.5 \mathrm{~g} / \mathrm{l})$ in water). The gradient procedure at a flow rate of $1 \mathrm{ml} / \mathrm{min}$ was as follows: $100 \%$ solvent $\mathrm{A}$ at time 0 , followed by a 6 min linear gradient to $60 \%$ solvent $\mathrm{A}$ and $40 \%$ solvent $\mathrm{B}$, a 6 min gradient to $100 \%$ solvent $\mathrm{B}$, a $5 \mathrm{~min}$ hold at $100 \%$ solvent $\mathrm{B}$, 1 min back to $100 \%$ solvent $\mathrm{A}$, and then a 6 min hold at $100 \%$ solvent A. In this HPLC system, retinol and retinyl palmitate eluted at $7 \cdot 1$ and 18.9 min respectively. 


\section{Retinyl ester hydrolase activities}

The bile salt analogue 3-((3-cholamidopropyl)dimethylammonio)-1-propane-sulfonate (CHAPS)-stimulated REH activity was measured in the liver and intestine. Conditions for measurement were adapted from Cooper et al. (1987) and Mercier et al. (1990) and determined before the analysis. Briefly, tissues were homogenized in ice-cold Trismaleate $(50 \mathrm{~mm})$. A portion of homogenate (about $300 \mu \mathrm{g}$ protein) was incubated in $100 \mathrm{~mm}$-Tris-maleate buffer (pH 7.5) in a shaking water-bath at $37^{\circ} \mathrm{C}$ for $90 \mathrm{~min}$. Incubation mixture contained $200 \mathrm{~mm}-\mathrm{CHAPS}$ in $100 \mathrm{mM}$-Trismaleate and $1.5 \mathrm{~mm}$-retinyl palmitate dispersed in Triton $\mathrm{x}-100(2 \mathrm{ml} / \mathrm{l})$, in a final volume of $0.2 \mathrm{ml}$. The reaction was stopped by the addition of $0.4 \mathrm{ml}$ ethanol; retinol in the incubation was then extracted and measured following the same HPLC procedure as for vitamin A determination. $\mathrm{REH}$ activity was calculated from the amount of retinol produced during the assay corrected for retinol formed in control incubations containing all assay components except the homogenate. The enzymatic activity of REH was expressed as nmol retinol liberated/mg protein per h.

Bile salt-independent REH activities in the liver, intestine and retina were conducted according to Tsin et al. (2000). Microsomal fraction was prepared from the tissue by differential centrifugation. Tissues were homogenized in ice-cold $0.25 \mathrm{mM}$-sucrose buffer, $\mathrm{pH} 7 \cdot 0$, containing 2 mM-dithiothreitol and $2 \mathrm{mM}$-EDTA. Homogenates of liver and intestine were first centrifuged at $27000 \mathrm{~g}$ for $20 \mathrm{~min}$ at $4^{\circ} \mathrm{C}$ (Sorvall RC-5B superspeed centrifuge; Dupont Instrument, Wilmington, DE, USA), and then at $125000 \mathrm{~g}$ for $90 \mathrm{~min}$ (Beckman Optima LE-80 K ultracentrifuge; Beckman Coulter, Inc., Fullerton, CA, USA). Homogenates of retina were centrifuged at $125000 \mathrm{~g}$ for $90 \mathrm{~min}$. The pellet was resuspended in $10 \mathrm{~mm}$-Tris-acetate buffer, $\mathrm{pH} 7 \cdot 5$, containing $2 \mathrm{mM}$-dithiothreitol and $2 \mathrm{mM}$ EDTA. The protein content in the sample was then determined. The reaction mixture $(200 \mu \mathrm{l})$ included $10 \mu \mathrm{l}$ 11-cis- $\left[{ }^{3} \mathrm{H}\right]$ retinyl palmitate containing 2 nmol substrate, $1-5 \mu \mathrm{g}$ protein and $50 \mathrm{~mm}$-Tris-acetate $(\mathrm{pH} 8)$. After a $30 \mathrm{~min}$ incubation at $37^{\circ} \mathrm{C}$, the reaction was stopped by the addition of $3 \mathrm{ml}$ methanol-chloroform-heptane
(1.41:1·25:1.00, by vol), followed by $1 \mathrm{ml} 50 \mathrm{mm-potass-}$ ium carbonate buffer ( $\mathrm{pH} 10)$. After the reaction mixture was centrifuged, $1 \mathrm{ml}$ upper phase was removed for liquid scintillation counting. Bile salt-independent REH activity was calculated as pmol palmitic acid liberated/ mg protein per min. Background correction was carried out by incubating substrate with denatured protein.

\section{Intestinal uptake of retinyl palmitate}

The intestinal uptake of retinyl ester was determined following the procedure described previously for free retinol (Tuitoek et al. 1994). Proximal and distal intestine (each $150 \mathrm{~mm}$ long) were removed as jejunum and ileum from $\mathrm{BBd}$ and corresponding control $(\mathrm{BBn})$ rats, immediately after killing. The intestinal segments were flushed with cold saline $(9 \mathrm{~g} \mathrm{NaCl} / \mathrm{l})$, cut into circular pieces, mounted as flat sheets in incubation chambers, and pre-incubated for $15 \mathrm{~min}$ in carbonated Krebs buffer at $37^{\circ} \mathrm{C}$. The chambers were then transferred to beakers containing $\left[15-{ }^{3} \mathrm{H}\right]$ retinyl palmitate (American Radiolabeled Chemicals, Inc., St Louis, MO, USA) at different concentrations ranging from 32 to $256 \mathrm{nM}$. $\left[{ }^{14} \mathrm{C}\right.$ ]Inulin carboxyl (NEN Life Science Products, Inc., Boston, MA, USA) was added in the incubation buffer as a non-absorbable marker. After incubation for $5 \mathrm{~min}$, the tissues were transferred to glass slides, dried overnight at $55^{\circ} \mathrm{C}$, weighed and saponified in $0.1 \mathrm{~mm}-\mathrm{NaOH}$. Scintillation fluid was then added and the radioactivities of the samples were counted after the correction for variable quenching of the two isotopes.

\section{Lipid analysis}

Plasma triacylglycerol and total cholesterol were determined using enzymatic kits from Sigma Biochemicals (catalogue no. 336 and no. 402 respectively). HDLcholesterol concentration was determined in the supernatant fraction of plasma sample following precipitation with HDL-cholesterol reagent (Sigma Biochemicals, catalogue no. 352). Liver triacylglycerol and total cholesterol were measured by the enzymatic methods of Carr et al. (1993) and Omodeo-Salè et al. (1984).

Table 1. Changes in general characteristics and plasma lipids with time in BB Wistar rats †‡

(Mean values with their standard errors for eight to ten rats per group)

\begin{tabular}{|c|c|c|c|c|c|c|c|c|c|c|c|c|}
\hline & \multicolumn{4}{|c|}{$30 \mathrm{~d}$} & \multicolumn{4}{|c|}{$50 d$} & \multicolumn{4}{|c|}{ Onset of diabetes } \\
\hline & \multicolumn{2}{|c|}{$\mathrm{BBn}(n 10)$} & \multicolumn{2}{|c|}{ BBdp $(n 10)$} & \multicolumn{2}{|c|}{$\mathrm{BBn}(n 10)$} & \multicolumn{2}{|c|}{ BBdp $(n 10)$} & \multicolumn{2}{|c|}{$\mathrm{BBn}(n 8)$} & \multicolumn{2}{|c|}{$\mathrm{BBd}(n 8)$} \\
\hline & Mean & SEM & Mean & SEM & Mean & SEM & Mean & SEM & Mean & SEM & Mean & SEM \\
\hline Food intake $(\mathrm{g} / \mathrm{d})$ & $10 \cdot 69$ & 0.64 & $10 \cdot 04$ & 0.54 & $15 \cdot 02$ & 0.68 & $16 \cdot 93$ & 0.69 & $20 \cdot 23$ & 0.58 & 21.42 & 0.53 \\
\hline Final body weight $(\mathrm{g})$ & $90 \cdot 5$ & 3.3 & $88 \cdot 4$ & $2 \cdot 5$ & $174 \cdot 6$ & $10 \cdot 8$ & $189 \cdot 1$ & $9 \cdot 1$ & $324 \cdot 6$ & $29 \cdot 3$ & 331.5 & $27 \cdot 2$ \\
\hline $\begin{array}{l}\text { Plasma }(\mathrm{mmol} / \mathrm{l}) \\
\text { Glucose }\end{array}$ & $6 \cdot 86$ & 0.30 & 6.77 & 0.14 & $10 \cdot 07$ & 0.59 & 9.58 & 0.47 & 9.50 & 0.30 & $15 \cdot 44^{*}$ & 0.58 \\
\hline Triacylglycerol & 0.74 & 0.12 & 0.79 & $0 \cdot 12$ & 0.52 & 0.04 & 0.46 & 0.04 & 0.80 & 0.09 & $1.37^{*}$ & 0.20 \\
\hline Total cholesterol & 1.77 & 0.07 & $2 \cdot 03^{*}$ & 0.09 & 1.50 & 0.09 & $1 \cdot 80^{*}$ & 0.06 & 1.65 & 0.08 & $2 \cdot 20^{\star \star}$ & 0.12 \\
\hline HDL-cholesterol & 0.92 & 0.04 & $1.07^{*}$ & 0.04 & 0.97 & 0.04 & $1 \cdot 15^{*}$ & 0.08 & 1.21 & 0.10 & 1.22 & 0.11 \\
\hline
\end{tabular}

BBn, non-diabetes-prone BB Wistar rats; BBdp, diabetes-prone BB Wistar rats; BBd, diabetic BB Wistar rats.

Mean values were significantly different from those of age- and sex-matched $\mathrm{BBn}$ rats: ${ }^{\star} P<0.05,{ }^{\star \star} P<0.01$.

$\dagger$ For details of diets and procedures, see p. 232.

$\ddagger \mathrm{BBdp}$ (or BBd) and age- and sex-matched BBn rats were killed at the age of $30 \mathrm{~d}, 50 \mathrm{~d}$ or at the onset of diabetes respectively. 


\section{Plasma glucose}

Plasma glucose level was measured by glucose oxidase method using kit from Sigma Biochemicals (catalogue no. 315$)$.

\section{Protein analysis}

Total protein in tissue homogenate was quantified by using the bicinchoninic acid protein assay (Pierce Co., Rockford, IL, USA). Bovine serum albumin was used as the protein standard.

\section{Statistical analysis}

Results were expressed as mean values with their standard errors. Comparisons (eight to ten rats per group) were made between BBdp (or BBd) and age- and sex-matched BBn rats using unpaired student $t$ test by SAS software (version 7.0; SAS Institute Inc., Cary, NC, USA). The significant level was set at $P<0 \cdot 05$.

\section{Results}

The incidence of diabetes among BBdp rats was $47 \%$; the earliest age of onset was $73 \mathrm{~d}$ and the latest $109 \mathrm{~d}$ of age with a mean value of $90 \mathrm{~d}$. Average daily food intake and final body-weight gain were not significantly different in BBdp rats at 30 and $50 \mathrm{~d}$ (pre-diabetic stage) as well as in $\mathrm{BBd}$ rats (onset of diabetes) compared with their ageand sex-matched $\mathrm{BBn}$ rats (Table 1). As expected, BBd rats had significantly higher $24 \mathrm{~h}$ urine volume compared with that of the BBn at the onset $(77.6$ (SE 16.8) v. 9.5 (SE 2.9) $\mathrm{ml} / 24 \mathrm{~h}$ respectively, $P<0 \cdot 05$ ). Compared with that of the $\mathrm{BBn}$ control rats, plasma glucose levels were significantly $(P<0.05)$ increased in BBd rats at the onset of diabetes (Table 1). The plasma cholesterol levels were elevated in rats with or without the presence of diabetes, while triaclyglycerol levels were increased only in the presence of hyperglycaemia (Table 1). Compared with the control counterparts, both plasma and hepatic free retinol levels were significantly lower at the onset of diabetes $(\mathrm{BBd})$ but remained unaffected at the age of either 30 or $50 \mathrm{~d}$, when no hyperglycaemia was displayed (Fig. 1). However, there was no change in the level of hepatic retinyl palmitate, the major form of retinyl esters in the liver (results not shown). The value of the retinol:retinyl palmitate ratio in the liver did not differ significantly either between BBdp (or BBd) rats and the control counterparts during the study $(14.05$ v. $16.09 \%$ at $30 \mathrm{~d}, 16.39 v$. $12.10 \%$ at $50 \mathrm{~d}, 10.48$ v. $13.29 \%$ at the onset; $P>0.05)$.

In order to determine whether the hyperglycaemiaassociated decrease in the plasma and liver retinol levels is a reflection of hydrolysis of retinyl ester, the REH activities were measured in both the intestine and the liver. Using hepatic tissues from BBn rats, the optimal conditions for the measurements of the CHAPS-stimulated REH activity were determined. Protein concentration $(300 \mu \mathrm{g} /$ $0.2 \mathrm{ml}$ ) and incubation time $(90 \mathrm{~min})$ were in the linear part of the curve (Fig. 2). Optimal pH was shown to be 7.5. CHAPS and substrate retinyl palmitate concentrations
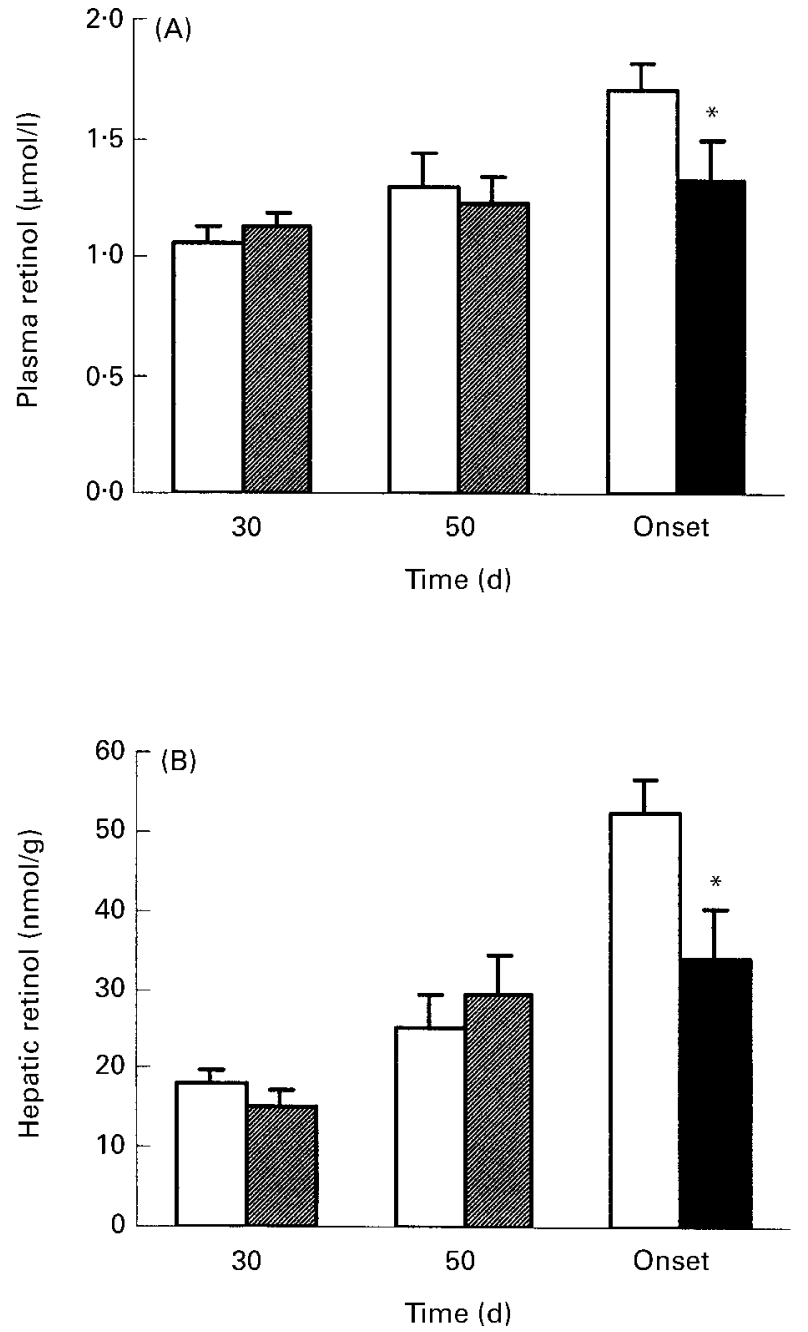

Fig. 1. Plasma $(A)$ and hepatic $(B)$ free retinol concentrations in $B B$ Wistar rats. Rats were killed at the age of $30 \mathrm{~d}, 50 \mathrm{~d}$ or at the onset of diabetes. $\square$, Non-diabetes-prone BB Wistar rats; diabetesprone BB Wistar rats; $\mathbf{a}$, diabetic BB Wistar rats. For details of diets and procedures, see p. 232. Values are means for at least eight rats with their standard errors shown by vertical bars. Mean values were significantly different from those of age- and sexmatched non-diabetes-prone BB control group: ${ }^{\star} P<0.05$.

(200.0 and $1.5 \mathrm{~mm}$ respectively) were chosen to give a maximal enzyme activity and a minimized variation coefficient simultaneously (results not shown). Under these conditions, kinetic variables for REH activity were determined, which showed an apparent $K_{\mathrm{m}} 0.54 \mathrm{~mm}$ and a maximal velocity of $10.8 \mathrm{nmol}$ retinol/h (Fig. 3).

CHAPS-stimulated REH activity was measured in tissues, including liver, jejunum and ileum, while bile salt-independent REH activity was also determined in the retina as well as these tissues. The hepatic activities of both CHAPS-stimulated (Fig. 4(A)) or bile salt-independent (Fig. 4(B)) REH activities were significantly decreased at the onset of diabetes in $\mathrm{BBd}$ rats compared with that of the $\mathrm{BBn}$ control. Thus the hepatic CHAPS-stimulated REH was 3.42 (SE 0.55) and 5.08 (SE 0.35) nmol retinol/ 

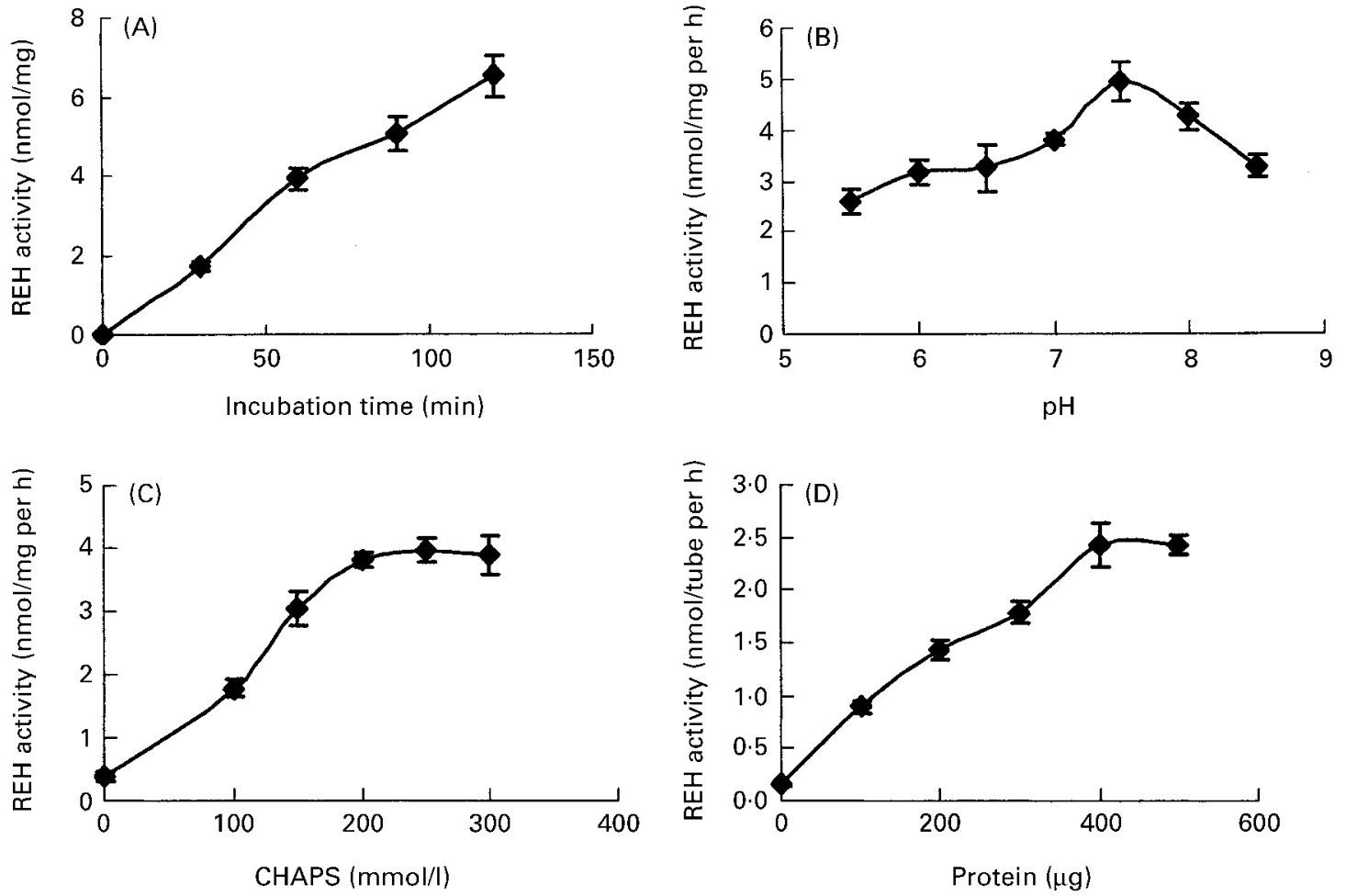

Fig. 2. Determination of the assay conditions for measuring 3-((3-cholamidopropyl)dimethylammonio)-1-propane-sulfonate (CHAPS)-stimulated retinyl ester hydrolase (REH). Incubations were carried out at $37^{\circ} \mathrm{C}$ in a final volume of $0.2 \mathrm{ml}$ in $0.1 \mathrm{~mm}$-Tris-maleate buffer. (A), effect of incubation time; (B), effect of $\mathrm{pH}$; (C), effect of the CHAPS concentration; (D), effect of protein concentration. For details of diets and procedures, see p. 232. Values are means for five or six different incubations with standard deviations represented by vertical bars.

mg per $\mathrm{h}(95 \% \mathrm{CI}: 2 \cdot 0,4 \cdot 8, v .4 \cdot 2,6 \cdot 0)$, and the bile saltindependent REH was 529 (SE 31.8) and 632 (SE 34.8) pmol palmitic acid/mg per min (95\% CI: 467, $591 v$. $583,681)$ in $\mathrm{BBd}$ and $\mathrm{BBn}$ rats, respectively. The changes in REH activities were, however, observed only in the liver, but not in the jejunum, ileum or retina (Fig. 4).

An in vitro study comparing the intestinal uptake between $\mathrm{BBd}$ and age-matched $\mathrm{BBn}$ rats was carried out. In that study, jejunal and ileal portions of the intestine were incubated with labelled retinyl palmitate at different concentrations within the physiological range $(<300 \mathrm{nM}$; Hollander \& Muralidhara, 1977). There was a linear relationship between the concentration and the rate of uptake of retinyl palmitate (Fig. 5). However, no difference in the rate of uptake was observed between $\mathrm{BBd}$ and $\mathrm{BBn}$ rats.

\section{Discussion}

The present study examined the changes in the biochemical status of retinol in BB Wistar rats before ( 30 and $50 \mathrm{~d}$ old) and at the onset of diabetes. The results demonstrated that both the hepatic and circulatory levels of retinol are decreased at the onset of diabetes, but not at the age of 30 and $50 \mathrm{~d}$. These results provide further evidence linking impaired vitamin A metabolism to type 1 diabetes. Retinol bound to RBP has been considered to be the physiologically important form of vitamin A transported in plasma and utilized by the target tissues (Blomhoff et al.
1990). Experimental (Tuitoek et al. 1996a,b; Lu et al. 2000) and clinical studies (Basu et al. 1989) have shown reduced plasma concentrations of retinol and RBP in the presence of a hyperglycaemic state. Furthermore, the hepatic expression of RBP mRNA is markedly decreased at the onset of diabetes in BB Wistar rats ( $\mathrm{Lu}$ et al. 2000). Thus, the biochemical evidence of low retinol levels in the presence of diabetes is thought to be caused by an impaired transport of the vitamin from its hepatic stores.

Vitamin A is obtained from dietary sources and is stored in the liver in its esterified form with fatty acids. The retinyl ester is normally hydrolysed by a variety of REH to free retinol before its metabolic availability (Blomhoff et al. 1990). In the present study, we investigated whether hyperglycaemia modifies the response of these REH at the onset of diabetes. The enzymatic activities of the hepatic, but not the intestinal, REH were depressed at the onset of diabetes in $\mathrm{BB}$ rats, suggesting that decreased hydrolysis of hepatic stores of vitamin A may contribute to the alteration of vitamin A status in diabetes.

A number of REH activities have been reported (Harrison \& Gad, 1989; Gueli et al. 1991; Rigtrup \& Ong, 1992). However, the relative role of these enzymes to a specific stage of vitamin A metabolism is not clearly understood. Among the REH activities, bile salt-independent $\mathrm{REH}$ is an enzyme that has been suggested to play a role at an initial stage of hepatic hydrolysis of chylomicron retinyl esters, based on its specific enrichment in plasma 

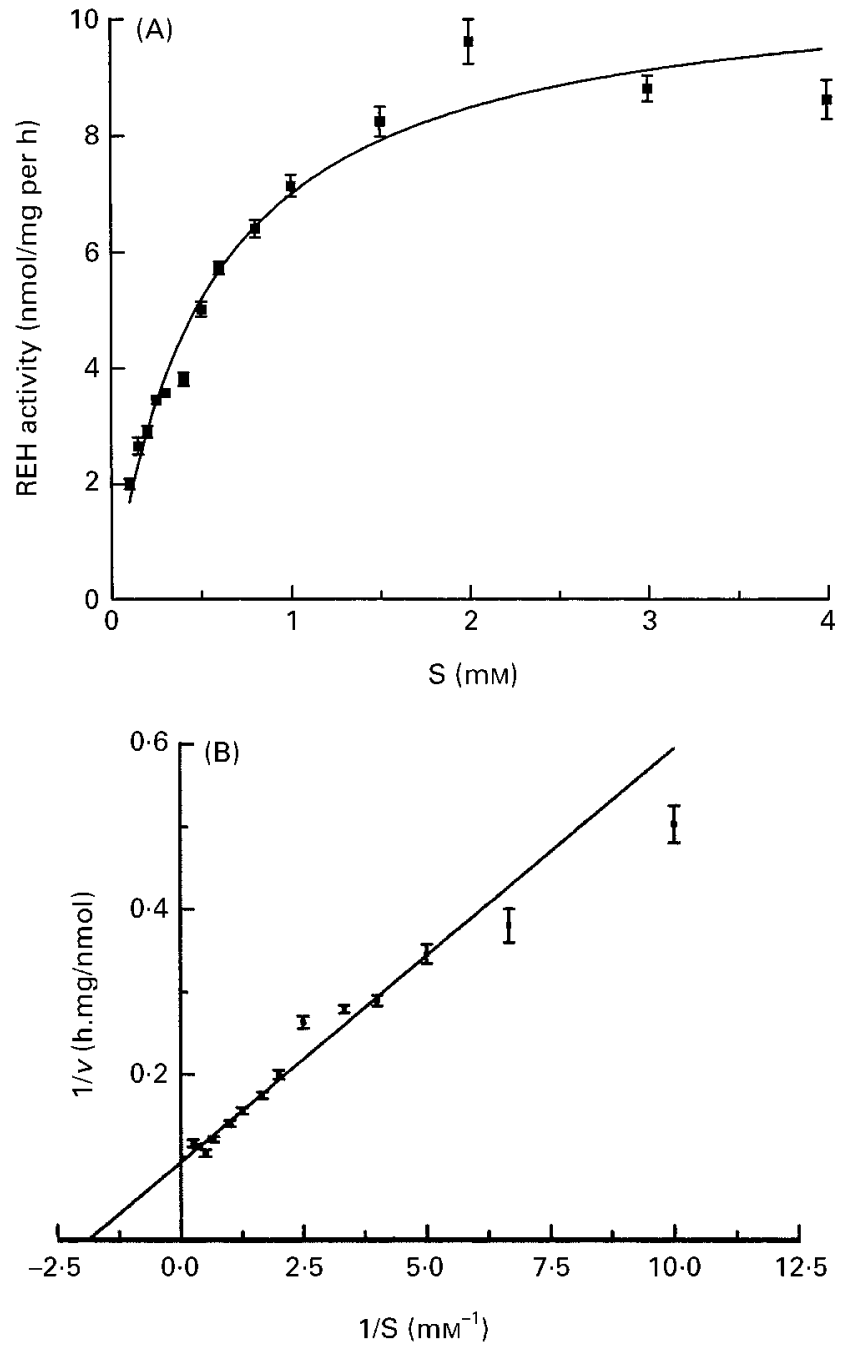

Fig. 3. (A), dependence of the 3-((3-cholamidopropyl)dimethylammonio)-1-propane-sulfonate (CHAPS)-stimulated retinyl ester hydrolase (REH) activity in rat liver homogenate on retinyl palmitate concentrations. For details of diets and procedures, see p. 232. Values are means for six different incubations with standard deviations represented by vertical bars. (B), Lineweaver-Burk plot of data. $\mathrm{S}$, substrate concentration; $v$, initial rate of reaction at a given value of $\mathrm{S}$.

membranes and/or endosomes (Ross, 1993). On the other hand, bile salt-dependent REH is thought to be highly related to carboxyl ester lipase, a bile salt-activated enzyme secreted by the pancreas and the liver. However, more recent studies (van Bennekum et al. 1999; Weng et al. 1999) have shown that the intestinal absorption of retinyl ester and hepatic uptake or metabolism of chylomicron retinyl esters are normal in carboxyl ester lipase knockout mice. These studies have suggested that a bile salt-dependent REH enzyme activity, distinct from carboxyl ester lipase, is present in the intestine as well as in the liver. Studies have also shown that hepatic lysosomal acid retinyl ester hydrolase, which can catalyse hydrolysis of retinyl esters in vitro, might be involved in the hydrolysis of the liver vitamin A stores (Mercier et al. 1994; Azais-Braesco et al. 1995). Another REH activity stimulated by CHAPS, a bile salt analogue, has been reported
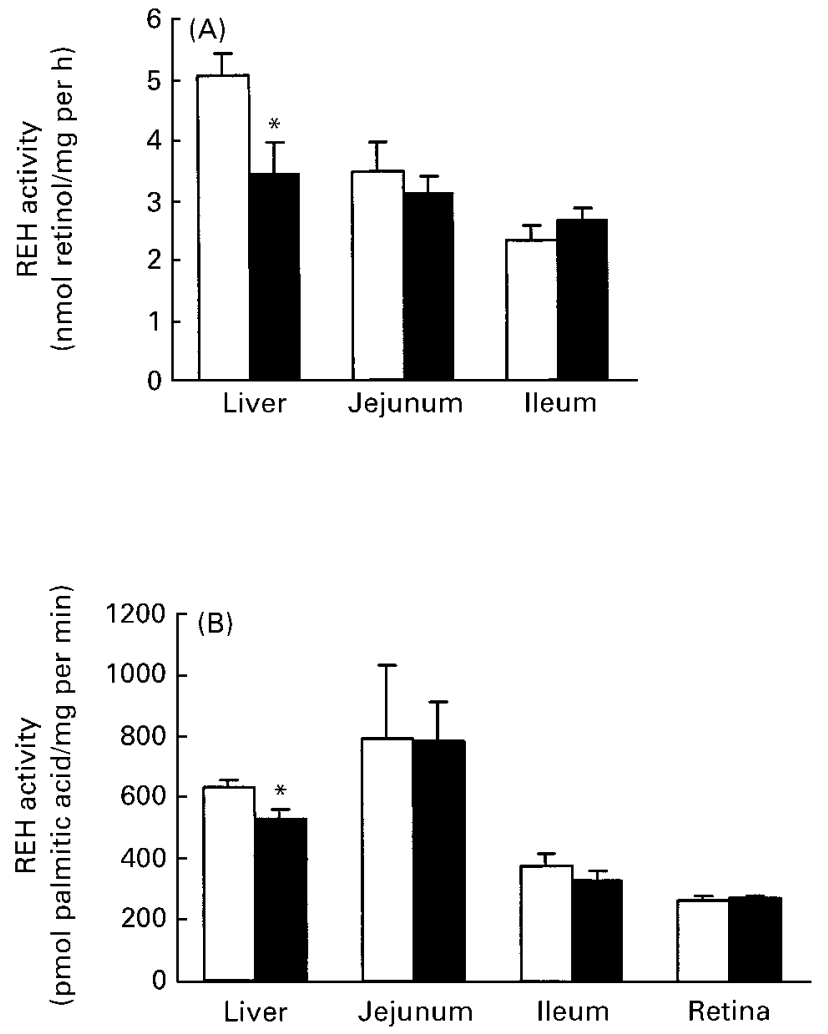

Fig. 4. (A), enzymatic activity of neutral retinyl ester hydrolase (REH) stimulated by bile salt analogue 3-((3-cholamidopropyl)dimethylammonio)-1-propane-sulfonate (CHAPS) in the liver, jejunum and ileum in diabetes-prone ( $\square$ ) and non-diabetes-prone ( $\square$ ) BB Wistar rats at the onset of diabetes. (B), neutral bile salt-independent REH activity in liver, jejunum, ileum and retina in diabetesprone $(\square)$ and non-diabetes-prone ( $\square$ ) BB Wistar rats at the onset of diabetes. For details of diets and procedures, see p. 234. Values are means for eight rats with their standard errors shown by vertical bars. Mean values were significantly different from those of ageand sex-matched non-diabetes-prone BB control group: ${ }^{*} P<0.05$.

in pigs (Cooper \& Olson, 1986) and rats (Cooper et al. 1987). It is still unclear whether the CHAPS-stimulated REH shares some similar characteristics with bile salt-dependent or bile salt-independent REH.

In the present study, both bile salt-independent and CHAPS-stimulated REH activities were measured in the liver of $\mathrm{BB}$ rats. Like the changes of plasma and hepatic retinol concentrations, the REH activities were reduced in the liver when the rats manifested the first sign of hyperglycaemia. No enzymatic activity change of CHAPSstimulated REH was observed in the liver of BBdp rats compared with that of BBn control at the age of $50 \mathrm{~d}$. The observations reported here suggest that the alteration of vitamin A status in the presence of diabetes is not only linked to an inadequate availability of retinol carrier proteins, as reported elsewhere (Tuitoek et al. 1996a; Lu et al. 2000), but also to the depressed REH activities in the liver.

Unlike in the liver, the onset of diabetes in BB rats had no effect on the bile salt-independent and CHAPSstimulated REH activities in either the jejunum or ileum. It is noteworthy, however, that in addition to the REH there are many enzymes that are thought to be involved 

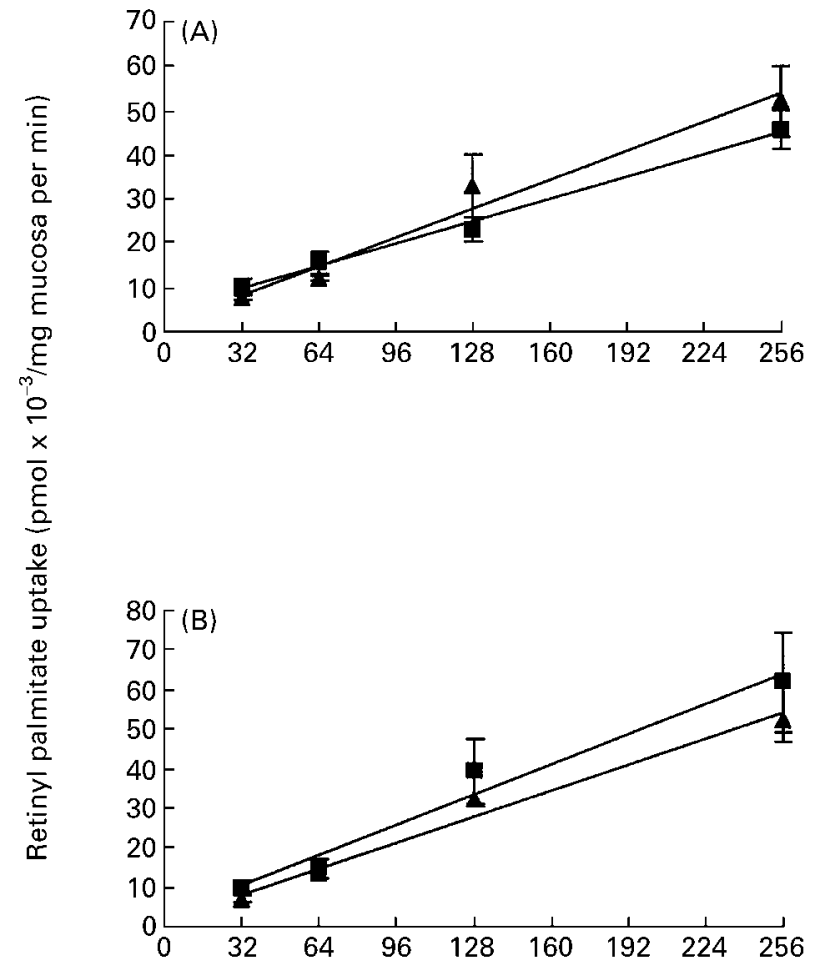

Retinyl palmitate concentartion ( $\mathrm{nmol} / \mathrm{I}$ )

Fig. 5. The uptake of retinyl palmitate into the jejunum $(A)$ and ileum (B) at different retinyl palmitate concentrations in diabetesprone $(\boldsymbol{\square})$ and non-diabetes-prone $(\boldsymbol{\Delta})$ BB Wistar rats at the onset of diabetes. For details of diets and procedures, see p. 232. Values are means for six rats with their standard errors shown by vertical bars.

in the digestion of dietary retinyl esters; these include pancreatic lipase, pancreatic carboxyl ester lipase and phospholipase B (Mentlein \& Heymann, 1987; Chen et al. 1997). An in vitro intestinal uptake study was therefore conducted by using labelled retinyl palmitate.

A previous study has shown that the intestinal uptake of labelled free retinol is not affected by streptozotocin-induced hyperglycaemia in rats (Tuitoek et al. 1994). In the present study, labelled retinyl palmitate was used instead of retinol, because the long-chain fatty acid ester of retinol is the major form of preformed vitamin $\mathrm{A}$ in a diet, and this ester must be hydrolysed before it is taken up by the enterocyte. The observations made in the present in vitro study involving retinyl palmitate are in accordance with those reported with free retinol. There was a linear relationship between the concentration and uptake of retinyl palmitate by the jejunum or the ileum, but there was no difference between diabetic and nondiabetic $\mathrm{BB}$ rats. These results suggest that intestinal absorption of vitamin A does not account for the decreased plasma or hepatic retinol status, reported here in diabetic $\mathrm{BB}$ rats.

This is the first report providing evidence that both the plasma and liver concentrations of free retinol, along with the hepatic REH activities, are not depressed until the onset of diabetes in BB Wistar rats. The decreased metabolic availability of vitamin $\mathrm{A}$ in the presence of hyperglycaemia has been suggested to be linked to an alteration in the hepatic synthesis of retinol carrier proteins (Tuitoek et al. 1996a; Lu et al. 2000). The present study provides evidence that a decreased REH activity in the liver contributes to diabetes-associated metabolic derangement of the vitamin.

\section{Acknowledgement}

This research was supported by the Natural Sciences and Engineering Research Council (NSERC) of Canada.

\section{References}

Azais-Braesco V, Dodeman I, Delpal S, Alexandre-Gouabau MC, Partier A, Borel P \& Grolier P (1995) Vitamin A contained in the lipid droplets of rat liver stellate cells is substrate for acid retinyl ester hydrolase. Biochimica et Biophysica Acta 1259, 271-276.

Bach JF (1988) Mechanisms of autoimmunity in insulindependent diabetes mellitus. Clinical and Experimental Immunology 72, 1-8.

Basu TK, Tze WJ \& Leichter J (1989) Serum vitamin A and retinol-binding protein in patients with insulin-dependent diabetes mellitus. American Journal of Clinical Nutrition 50, 329-331.

Baudon MA, Ferre P, Penicaud L, Maulard P, Ktorza A, Castano L \& Girard J (1989) Normal insulin sensitivity during the phase of glucose intolerance but insulin resistance at the onset of diabetes in the spontaneously diabetic BB rat. Diabetologia 32, 839-844.

Blomhoff R, Skrede B \& Norum KR (1990) Uptake of chylomicron remnant retinyl ester via the low-density lipoprotein receptor: implications for the role of vitamin A as a possible preventive for some forms of cancer. Journal of Internal Medicine 228, 207-210.

Carr TP, Andresen CJ \& Rudel LL (1993) Enzymatic determination of triglyceride, free cholesterol, and total cholesterol in tissue lipid extracts. Clinical Biochemistry 26, 39-42.

Chen X, Harrison EH \& Fisher EA (1997) Molecular cloning of the cDNA for rat hepatic bile salt-dependent cholesteryl ester/retinyl ester hydrolase demonstrates identity with pancreatic carboxylester lipase. Proceeding of the Society of Experimental Biology and Medicine 215, 186-191.

Cooper DA, Furr HC \& Olson JA (1987) Factors influencing the level and interanimal variability of retinyl ester hydrolase activity in rat liver. Journal of Nutrition 117, 2066-2071.

Cooper DA \& Olson JA (1986) Properties of liver retinyl ester hydrolase in young pigs. Biochimica et Biophysica Acta 884, 251-258.

Gueli MC, Nicotra CM, Pintaudi AM, Paganini A, Pandolfo L, De Leo G \& Di Bella MA (1991) Retinyl ester hydrolases in retinal pigment epithelium. Archives of Biochemistry and Biophysics 288, 572-577.

Harrison EH \& Gad MZ (1989) Hydrolysis of retinyl palmitate by enzymes of rat pancreas and liver. Differentiation of bile saltdependent and bile salt-independent, neutral retinyl ester hydrolases in rat liver. Journal of Biological Chemistry 264, $17142-17147$.

Hollander D \& Muralidhara KS (1977) Vitamin A $A_{1}$ intestinal absorption in vivo: influence of luminal factors on transport. American Journal of Physiology 232, E471-E477.

Hosszufalusi N, Chan E, Teruya M, Takei S, Granger G \& Charles MA (1993) Quantitative phenotypic and functional 
analyses of islet immune cells before and after diabetes onset in the BB rat. Diabetologia 36, 1146-1154.

Krempf M, Ranganathan S, Ritz P, Morin M \& Charbonnel B (1991) Plasma vitamin A and E in Type 1 (insulin-dependent) and Type 2 (non-insulin-dependent) adult diabetic patient. International Journal of Vitamin and Nutrition Research 61, $38-42$.

Logothetopoulos J, Valiquette N, Madura E \& Cvet D (1984) The onset and progression of pancreatic insulitis in the overt, spontaneously diabetic, young adult BB rat studied by pancreatic biopsy. Diabetes 33, 33-36.

Lu J, Dixon WT, Tsin AT \& Basu TK (2000) The metabolic availability of vitamin $\mathrm{A}$ is decreased at the onset of diabetes in BB rats. Journal of Nutrition 130, 1958-1962.

Martinoli L, Di Felice M, Seghieri G, Ciuti M, De Giorgio LA, Fazzini A, Gori R, Anichini R \& Franconi F (1993) Plasma retinol and alpha-tocopherol concentrations in insulindependent diabetes mellitus: their relationship to microvascular complications. International Journal of Vitamin and Nutrition Research 63, 87-92.

Mentlein R \& Heymann E (1987) Hydrolysis of retinyl esters by non-specific carboxylesterases from rat liver endoplasmic reticulum. Biochemical Journal 245, 863-867.

Mercier M, Forget A, Grolier P \& Azais-Braesco V (1994) Hydrolysis of retinyl esters in rat liver. Description of a lysosomal activity. Biochimica et Biophysica Acta 1212, 176-182.

Mercier M, Pascal G \& Azais-Braesco V (1990) Retinyl ester hydrolase and vitamin A status in rats treated with 3,3',4,4'tetrachlorobiphenyl. Biochimica et Biophysica Acta 1047, 70-76.

Omodeo-Salè F, Marchesini S, Fishman PH \& Berra B (1984) A sensitive enzymatic assay for determination of cholesterol in lipid extracts. Analytical Biochemistry 142, 347-350.

Ong DE (1993) Retinoid metabolism during intestinal absorption. Journal of Nutrition 123, Suppl. 2, 351-355.

Parfrey NA, Prud'homme GJ, Colle E, Fuks A, Seemayer TA, Guttmann RD \& Ono SJ (1989) Immunologic and genetic studies of diabetes in the BB rats. Critical Review of Immunology 9, 45-65.

Rigtrup KM \& Ong DE (1992) A retinyl ester hydrolase activity intrinsic to the brush border membrane of rat small intestine. Biochemistry 31, 2920-2926.

Ross AC (1993) Overview of retinoid metabolism. Journal of Nutrition 123, Suppl. 2, 346-350.

Tsin AT, Mata NL, Ray JA \& Villazana ET (2000) Substrate specificities of retinyl ester hydrolases in retinal pigment epithelium. Methods of Enzymology 316, 384-400.

Tuitoek PJ, Ritter SJ, Smith JE \& Basu TK (1996a) Streptozotocin-induced diabetes lowers retinol-binding protein and transthyretin concentrations in rats. British Journal of Nutrition 76, 891-897.

Tuitoek PJ, Thomson ABR, Rajotte RV \& Basu TK (1994) Intestinal absorption of vitamin A in streptozotocin-induced diabetic rats. Diabetes Research 25, 151-158.

Tuitoek PJ, Ziari S, Tsin AT, Rajotte RV, Suh M \& Basu TK (1996b) Streptozotocin-induced diabetes in rats is associated with impaired metabolic availability of vitamin A. British Journal of Nutrition 75, 615-622.

Uehara F, Yasumura D \& LaVail MM (1989) New isolation method of retina and interphotoreceptor matrix. Experimental Eye Research 49, 305-309.

van Bennekum AM, Li L, Piantedosi R, Shamir R, Vogel S, Fisher EA, Blaner WS \& Harrison EH (1999) Carboxyl ester lipase overexpression in rat hepatoma cells and CEL deficiency in mice have no impact on hepatic uptake or metabolism of chylomicron-retinyl ester. Biochemistry 38, 4150-4156.

Wang XD, Liu C, Chung J, Stickel F, Seitz HK \& Russell RM (1998) Chronic alcohol intake reduces retinoic acid concentration and enhances AP-1 (c-Jun and c-Fos) expression in rat liver. Hepatology 28, 744-750.

Weng W, Li L, ven Bennekum AM, Potter SH, Harrison EH, Blaner WS, Breslow JL \& Fisher EA (1999) Intestinal absorption of dietary cholesteryl ester is decreased but retinyl ester absorption is normal in carboxyl ester lipase knockout mice. Biochemistry 38, 4143-4149. 